\title{
Los reales de minas de la caja de Guadalajara durante el siglo XVIII: Circuitos comerciales y producción de plata ${ }^{1}$
}

\author{
por \\ C. René de León Meza \\ Universidad de Guadalajara, CUCEA \\ Departamento de Sociales y Jurídicas
}

Este artículo da a conocer la importancia económica que tuvo un conjunto de reales de minas que perteneció a la jurisdicción de la caja de Guadalajara. Es novedoso porque por primera vez son estudiados aquéllos que la historiografía local ha considerado erróneamente como «pequeños reales de minas». Estas explotaciones fueron el eje articulador de la economía en una vasta región que impulsó el desarrollo de la ganadería, agricultura y comercio. Vincula las fluctuaciones en la producción de plata con sucesos ocurridos en Europa.

PAlabras Claves: Plata; aviadores; mineros; comercio; mercurio.

\section{INTRODUCCIÓN}

Apenas concluida la guerra de conquista de Nuño Beltrán de Guzmán por el territorio que después sería conocido como reino de la Nueva Galicia², algunos de sus capitanes iniciaron una nueva cruzada para obtener de las entrañas de la tierra oro y plata. En la década de 1540 a 1550 se descubrieron ricos yacimientos de esos metales. Desde el primer año de explotación minera y debido a la cantidad de plata que se sacaba, la corona española ordenó el establecimiento de una caja real en la ciudad de Compostela para que ahí acudieran los

\footnotetext{
1 Dedicado al Dr. Antonio Ibarra como agradecimiento por la inmensurable confianza que siempre ha depositado en mi trabajo.

2 Ese reino comprendía lo que ahora son los estados de Jalisco, Nayarit, Zacatecas, Aguascalientes y parte de Sinaloa.
} 
mineros a pagar los impuestos correspondientes de sus metales. Pocos años después, en 1560, la caja real se trasladó a la ciudad de Guadalajara al convertirse en la capital del reino de la Nueva Galicia y ahí permaneció hasta el fin de la dominación española.

La primera mina explotada en territorio neogallego fue la del Espíritu Santo, descubierta en 1540 (cercana a la ciudad de Compostela) y famosa por la calidad de su plata, aunque también se sacaba oro. Tres años después, Cristóbal de Oñate descubrió las minas de oro de Xaltepec, mientras que Juan Fernández de Hijar inició una serie de explotaciones en Guachinango, Etzatlán, Guajacatlán, Xocotlán y La Purificación. En los años postreros de esa década fueron descubiertas otras en Jora, San Pedro Analco, Ameca, Chimaltitán, Ocotitlán, Los Frailes, El Rojo, Tinamache, Hostotipaquillo y Ostotipac.

La característica de esa primera bonanza en aquellas minas fue la abundante cantidad y calidad de sus metales. La propietaria de la mina del Espíritu Santo amasó durante los primeros cinco años de explotación una considerable fortuna que le permitió dotar a cada una de sus tres hijas con cien mil pesos al casarlas. Gracias a la plata de esa mina, un nieto de la primera dueña logró comprar el título de conde de Miravalle (único título de nobleza adquirido gracias a la riqueza de las minas de la caja de Guadalajara). Fray Antonio Tello escribió que «era tanta la plata que de aquellas minas se sacaba, que llevaban recuas cargadas a México, de la misma manera como agora se trajina la sal y el pescado»3.

Fray Diego Muñoz en su Descripción de las provincias de San Pedro y San Pablo, escrita en 1583, mencionaba que de esas minas «se ha sacado mucha y rica plata que tocaba en oro $»^{4}$. Por su parte, los reales de Guachinango, Guajacatlán, Etzatlán y Taotlán rindieron durante los primeros 30 años de explotación «más de dos millones a su majestad por sus reales derechos» ${ }^{5}$. En las minas de Xocotlán, la primera veta descubierta rindió de 5 a 6 marcos por quintal entre 1560 y $1680^{6}$. El registro fiscal más antiguo de la real caja de Guadalajara nos da una reminiscencia de aquella riqueza al indicar que en 1568 se recaudaron 176 mil 445 pesos por concepto de diezmo y quinto de plata ${ }^{7}$.

Esta riqueza y abundancia de las minas en la caja de Guadalajara declinó a fines del siglo XVI y jamás volvió a repetirse; pero eso no impidió que se

3 Tello, 1968: 390-391.

4 Muñoz, 1950: 56.

5 Esta información la dio a conocer el intendente de Guadalajara, Antonio Gutiérrez y Ulloa, en un informe que escribió a la corona española en 1816. Gutiérrez y Ulloa, 1983: 129.

6 Lang, 1977: 215.

7 Tepaske y Kleín, 1986, vol. 1: 1 . 
mantuvieran en explotación a lo largo de los siguientes dos siglos con sus respectivas bonanzas y borrascas, según las circunstancias y habilidades de los mineros ${ }^{8}$. Es justamente la larga duración en las explotaciones de estos reales de minas y su producción en conjunto, lo que me lleva a escribir este artículo con el objeto de analizar el papel que jugaron como articuladores de una amplia red comercial que vinculaba no sólo a los comerciantes, sino a hacendados, clérigos, militares, funcionarios públicos, etc. La importancia económica de estos reales de minas radicó en que su producción conjunta sirvió como abastecedora de circulante (en moneda o en barras) a los distintos mercados regionales de la provincia de Guadalajara.

Algunos aspectos importantes que se destacarán en este artículo serán la estructura productiva, el funcionamiento de los reales de minas, su gran dependencia de los créditos suministrados en especie por los aviadores y la producción anual de plata calculada a partir del impuesto del 1\% y diezmo cobrado en la caja de Guadalajara. El estimado de producción de plata a partir de esas cuentas fiscales no representa el monto global obtenido de ese metal, pues existieron muchas formas de evasión de impuestos. La más común e importante fue la que establecieron los mineros y comerciantes, basada en la transacción de plata en barras que muchas veces no pagaba impuesto. Aun así, las cifras obtenidas de impuesto registradas confirman que la industria minera fue la principal fuente de ingresos fiscales en esa región.

\section{ESTRUCTURA PRODUCTIVA Y FUNCIONAMIENTO}

La estructura productiva de la plata en la jurisdicción de la caja de Guadalajara a lo largo del siglo XVIII provenía de la explotación intensiva de más de doscientas minas agrupadas en una veintena de reales de minas y aproximadamente unas 40 haciendas de beneficio. Los reales de minas que aquí se estudian son los de Guachinango, Amatlán de Cañas, San Joaquín, San Nicolás, San Miguel de Atenguillo, Jora, Hostotipaquillo, El Limón, Etzatlán, Ahualulco, San Pedro Analco, Ostotipac, San Sebastián, San Rafael de Tapalpa, Ameca, Mascota, Chimaltitán, Jolapa, La Yesca, Los Reyes, Santa María Tequepexpan, Guajacatlán, El Carrizalillo, Acaponeta, Pijinto y Chiquilistlán9.

8 Varios de los centros mineros aquí estudiados continuaron explotándose hasta la cuarta década del siglo XX, logrando que el estado de Jalisco ocupara en esos año, los primeros lugares en producción de plata y oro.

9 Una descripción de esos reales de minas hecha en la última década del siglo XVIII nos permite conocer la ley de sus metales. En Guachinango, que se encontraba en decadencia y po- 
Es indudable que cada uno de estos reales de minas por sí solos, no tuvieron la importancia de otros como Zacatecas, Real del Monte, Guanajuato o Bolaños. La relevancia está al estudiarlos en conjunto y ver las cantidades que año con año aportaban por concepto de impuestos a la caja real. La plata que producían alentó a distintos personajes a participar en esta industria ya fuera de manera directa o como aviadores de los mineros. Esto propició la articulación de una amplia red comercial que involucraba a hacendados, mineros, comerciantes, autoridades civiles, eclesiásticas y militares, por la cual circulaban grandes cantidades de plata en barras o amonedada y una gran variedad de insumos.

Una característica de estos reales de minas fue la continuidad que tuvieron a lo largo de todo el siglo a pesar de una serie de adversidades o perjuicios que no había en otros reales de la Nueva España. El reparto de azogue es un claro ejemplo, pues aparte de que se daba preferencia a los grandes reales de minas en detrimento de los pequeños, éste llegaba en pocas cantidades y además se les exigía a los mineros una mayor cantidad de marcos quintados de plata por cada quintal de mercurio vendido. A los de la caja de Guadalajara se les exigían 125 marcos de plata por cada quintal de azogue. Esto significaba una desventaja al momento de querer comprar más azogue ya que si presentaban una cantidad menor, se le vendería menos en la siguiente asignación $^{10}$. Esta tarifa existente desde el siglo XVII, significaba para los mineros del siglo XVIII que el costo por producir un marco de plata fuera más costoso. Además, el precio del azogue les resultaba mucho más alto debido a los gastos de traslado desde la superintendencia de azogues a la caja de Guadalajara y de ahí a los distintos reales de minas. Pero sobre todo, ninguno de esos reales gozó nunca de las exenciones o beneficios fiscales que la corona otorgó a mineros importantes de la Nueva España. Por último, la ubicación geográfica de ellos, lejanos de la ciudad de Guadalajara, ocasionaba que los insumos fueran más gravosos, reduciendo por consiguiente la ganancia de los mineros. Resultaba menos costoso obtener un marco de plata en Pachuca que en Ostotipac por ejemplo.

breza debido a su baja ley, se obtenían de 2 a 2,5 onzas de plata por carga. En San Joaquín su ley rica era de 5 onzas por carga. En El Rojo de 2 a 4 onzas. En San Sebastián 4 onzas a lo mucho, mientras que en Chimaltitán el promedio estaba entre 4 y 6 onzas por carga. Menéndez Valdés, 1980: 79-98.

${ }^{10}$ Los mineros de Guanajuato, Durango y Guadalajara eran los que más cantidad de marcos de plata tenían que quintar por un quintal de Azogue. A los de Zacatecas, Sichu, Pachuca se les pedían 100 marcos y a otros, cantidades todavía menores. Lang, 1977: 215. 
El funcionamiento de esos reales de minas estaba basado en el crédito que los mineros obtenían de un grupo heterogéneo de prestamistas encabezados por casi todos los comerciantes de Guadalajara, aunque también los hubo de otras ciudades como México, Guanajuato y Zacatecas. En menor medida que los comerciantes, otro conjunto de aviadores lo conformaron los hacendados, clérigos, militares y funcionarios públicos. La participación de los mercaderes como aviadores se distinguía porque no se involucraban como socios de los mineros, eran únicamente sus prestamistas. Si al minero le iba mal y no pagaba su deuda, perdía su propiedad para que el comerciante recuperara el dinero que había prestado. Por el contrario, los otros aviadores se involucraban como socios capitalistas en donde a cambio de un préstamo, recibían acciones de una mina o hacienda de beneficio. Si ésta no redituaba ganancias, perdían lo invertido o prestado.

La relación minero-aviador era de mutua dependencia pues los reales de minas representaban un mercado consumidor seguro de las mercancías de los comerciantes y hacendados. La mayoría de estos convenios iniciaba cuando algún ciudadano descubría algún mineral que prometía tener buena y abundante ley. Después de denunciar su hallazgo y obtener la posesión, inmediatamente buscaba algún comerciante o persona con dinero que financiara su proyecto. El aviador exigía como primer requisito que el solicitante tuviera alguna propiedad con que respaldar la cantidad prestada y posteriormente se establecían los plazos a pagar, con un interés anual del $5 \%$.

En general los préstamos eran por cantidades que fluctuaron entre los 5 y 10 mil pesos, muy pocos alcanzaron los 25 mil pesos y al menos dos casos, superaron la suma de cincuenta mil pesos. A cambio de estos préstamos, los dueños de minas o haciendas de beneficio debían hipotecar algunas propiedades agrícolas o ganaderas y aun sus explotaciones mineras. Cuando los plazos para pagar se cumplían y el deudor no cubría el monto, se daban dos situaciones mediante las cuales los aviadores recuperaban toda o la mayor parte de su dinero. Una de ellas era la de establecer un acuerdo mediante el cual el deudor cedía sus instalaciones a su acreedor para que éste las trabajara durante un tiempo determinado y así con la plata beneficiada recuperara lo que había prestado con sus respectivos intereses. Un ejemplo puede ilustrar mejor esta situación. El minero Juan José Indiano era dueño de una rica mina en el real de La Yesca, jurisdicción de Hostotipaquillo. En ese lugar poseía una hacienda de beneficio por el sistema de fuego. Durante varios años estuvo recibiendo préstamos del comerciante Andrés Ignacio de Arzamendi. En 1782, cuando la deuda alcanzó la cantidad de 65.289 pesos, llegaron al acuerdo de que el minero le cediera la administración de la mina y hacienda hasta que la plata producida cubriera la deuda. Gracias a «la buena ley y abundancia de metales en su 
mina» la deuda se cubrió en el tiempo de un año 3 meses y las propiedades fueron devueltas a su propietario ${ }^{11}$.

La otra forma que se daba para que los aviadores recuperaran el dinero prestado, era mediante el embargo de sus propiedades para luego rematarlas a otros mineros con los cuales iniciaban una nueva relación crediticia. Así actuaba el almacenero de la ciudad de México Juan Martínez de Viedma, que era uno de los principales aviadores de mineros a mediados del siglo XVIII. En una ocasión en 1736, despojó a un minero de tres haciendas de beneficio y una mina ubicadas en el real de Guachinango y se las vendió a otra persona. Por eso, una de las características de esos reales era la de un constante cambio de dueños en las instalaciones sin que se suspendieran las labores.

Esta relación convenía a ambas partes. A los mineros porque los avíos que requerían les eran entregados en sus mismas instalaciones casi siempre a crédito y pagaban hasta que tenían la plata en barras. Los comerciantes, en cambio, obtenían la exclusiva de instalar una tienda para vender sus mercancías también a los trabajadores asegurando así la obtención de la plata tanto de los trabajadores como de los dueños de las minas cuando pagaban sus deudas. $\mathrm{Su}$ negocio era vender a altos precios y recibir la plata beneficiada por debajo de su valor real. El aviador por lo general, tomaba la plata de los mineros a razón de siete pesos el marco, pero hubo casos en que la recibía a seis pesos y medio y a 5,5 pesos $^{12}$.

Este acuerdo en apariencia tan desventajoso para el minero, no lo era tanto si calculamos los gastos y riesgos que tendría que solventar al llevar su plata a quintar directamente a la caja real de Guadalajara. Pago de arrieros, esperar el tiempo en que la plata llegara a esa ciudad, el riesgo de que le fuera robada en los caminos que estaban infestados de asaltantes, pero sobre todo, el tiempo que esperaban para que su plata fuera enviada a acuñar a la casa de moneda de México y su regreso. Por esos inconvenientes, creo que preferían hacer la transacción directamente con los comerciantes aunque se las tomaran a un precio menor de su valor. Es por ello que, al momento de calcular los montos de producción a partir de los ingresos fiscales, se debe tomar en cuenta esa plata en barras que pasaba a manos de los comerciantes y que no llegaba a la caja real.

11 La plata producida le fue tomada al minero a razón de 6-6-0 pesos el marco. Acuerdo para pago de deuda, Biblioteca Pública del Estado de Jalisco, Real Audiencia de Guadalajara (BPEJ-RAG), Ramo Civil, expediente 118-2-1260.

12 En 1736 por ejemplo, el comerciante de Guadalajara le prestó a un minero del real de Las Mojarras la cantidad de 25,247 pesos con la condición expresa de que se los pagara con la plata producida a razón de siete pesos por cada marco. Contrato de avio, Archivo de Instrumentos Públicos de Guadalajara (AIPG), Manuel de Mena, vol. 24, f. 271f-275v. 
Mapa 1. Reales de Minas de la nueva Galicia en el siglo XVIII*

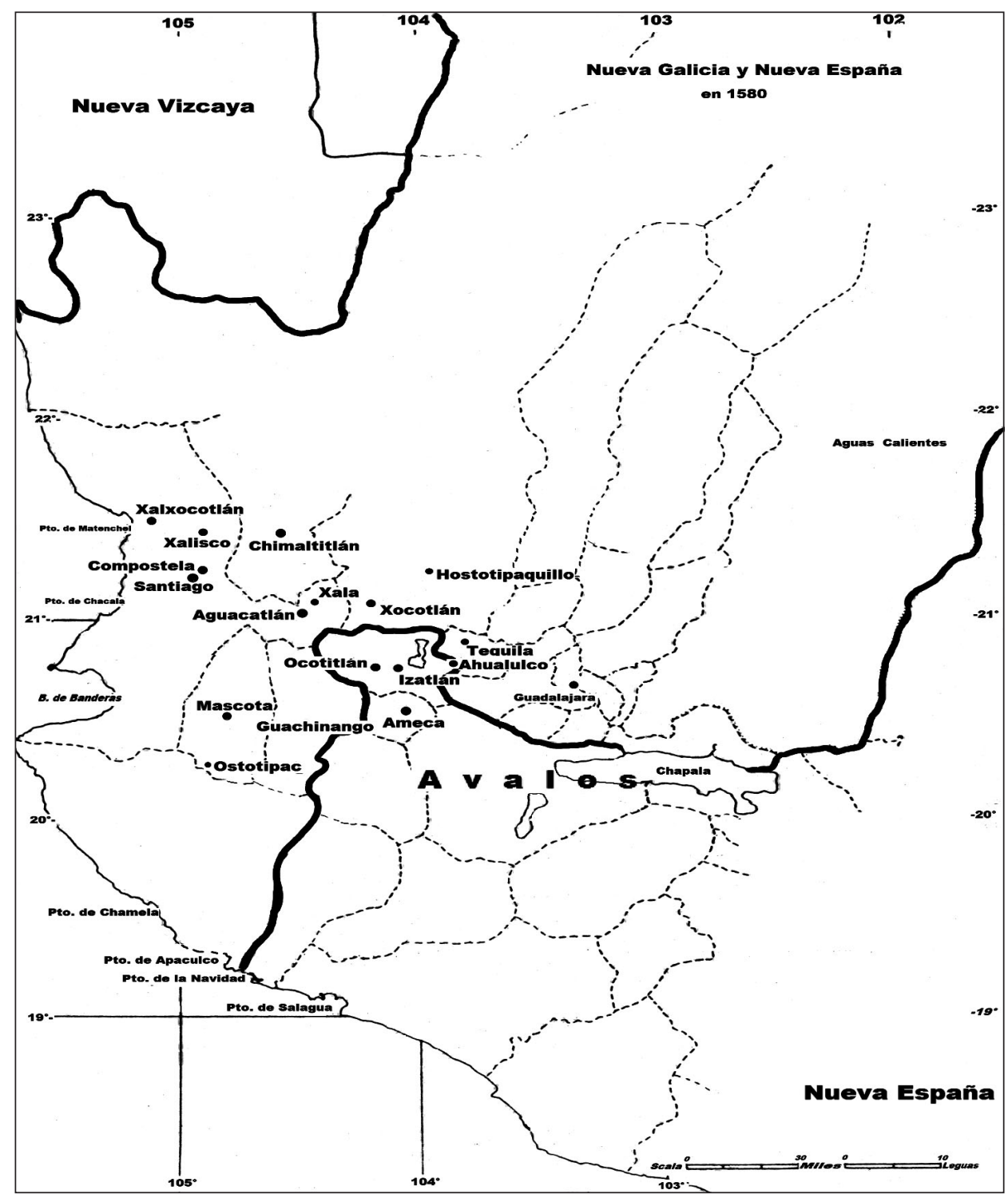

Fuente: Acuña, 1988: 9.

* El mapa y los gráficos de este artículo fueron elaborados por Elisabeth Hinojosa López. 
Un rasgo distintivo de la relación minero-aviador en esas minas fue que normalmente un aviador financiaba al mismo tiempo a varios mineros en diferentes reales, probablemente porque uno sólo no representaba la obtención de ganancias considerables. Entre 1730 y 1740, el rico mercader Francisco de Castro había prestado a distintos mineros de Hostotipaquillo, Tequepexpan, Tequila, Guajacatán y Etzatlán la cantidad de 41.962 pesos.

Los numerosos contratos de avíos para mineros que se resguardan en los libros de notarios de Guadalajara refutan lo que la historiadora Linda Grenow afirmó respecto a que los mineros de la Nueva Galicia durante el siglo XVIII no fueron grandes solicitantes de crédito, excepto en los años de 1760-70 cuando esos préstamos sirvieron para financiar las inversiones mineras en Bolaños y Zacatecas ${ }^{13}$. Si sumamos las cantidades de 49 contratos de avíos para mineros de la caja de Guadalajara y los comparamos con los que la historiadora aporta, los resultados son muy diferentes como se puede observar en la siguiente gráfica.

Gráfica 1. Dinero prestado a mineros de Guadalajara En El Siglo XVIII. Pesos

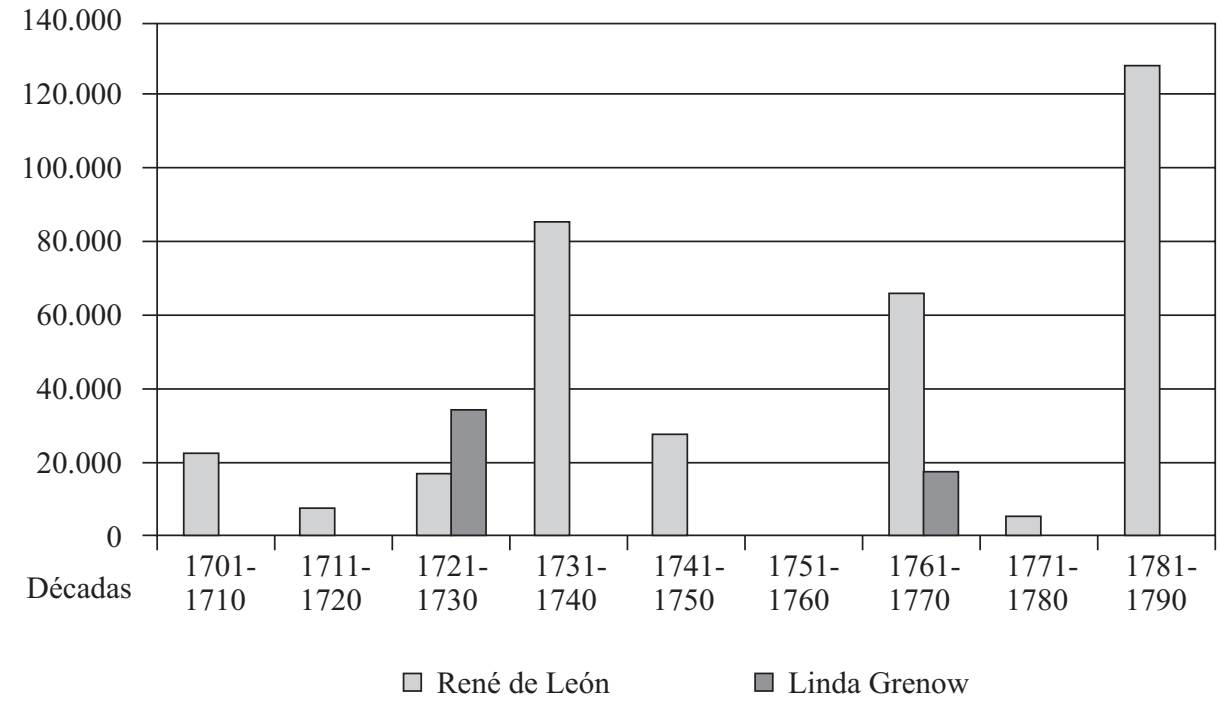

Fuente: AIPG, Grenow, 1980: 70-71.

13 Grenow, 3 (Guadalajara, octubre-diciembre 1980): 70-71. 
No siempre las relaciones mineros-aviadores terminaban con la pérdida de las propiedades de los primeros. Hubo casos de hábiles mineros que supieron conjuntar muy bien las facilidades ofrecidas por el crédito, los conocimientos teóricos con la práctica que se reflejaron en las obras y tecnología aplicada en las minas y utilizar las relaciones familiares como estrategias comerciales para convertir a la industria minera en la fuente de ingresos fiscales más importante de la real caja de Guadalajara durante la centuria aquí estudiada. Uno de esos mineros fue Juan Eugenio Santelises Pablo, propietario de todas las minas y haciendas de beneficio en el real de San Rafael de Tapalpa, en la alcaldía mayor de Sayula. Su participación en ese real inició como aviador de varios mineros, después, los dueños le fueron donando acciones en varias de ellas como forma de pago, hasta que finalmente les compró el resto de las acciones.

Santelises estaba convencido de que la única manera de lograr que su empresa fuera redituable era la de realizar fuertes inversiones en infraestructura minera. Para evitar las inundaciones de sus minas, desvió el cauce de un río que pasaba justo debajo de la veta principal, construyó un dique de piedra para contener sus aguas, perforó varios tiros, unos con la finalidad de desaguar las minas (uno de ellos de más de 300 varas) y otros para la saca del mineral. En estos últimos instaló varios malacates. En algunas de sus minas realizó nuevas tientas y excavaciones, perforándolas más de 25 metros de lo que ya tenían. Ademó los tiros y socavones, construyó lumbreras, fabricó y equipó tres haciendas de beneficio, dos de azogue y una de fuego ${ }^{14}$.

Casi cien años después de estas obras, en 1879, la compañía encargada de la explotación de metales en el real de San Rafael encargó al ingeniero Juan Ignacio Matute un estudio sobre las minas que se habían trabajado antiguamente. En su informe final, Matute escribió sobre la desviación del cauce del río: «esa obra debe de haber tenido algunas pintas de grande interés, puesto que dio motivo á los antiguos mineros á acometer una obra costosa, muy imprudente y no de grandes resultados, pues según la tradición les fue funesta: me refiero al tajo que hicieron para desviar el curso del arroyo, la construcción de un muro de mampostería de cincuenta metros de largo, cinco de ancho $y$ tres de espesor, el paso o bocamina que abrieron en el mismo lecho del arroyo, el cual en una creciente extraordinaria, invadió el pozo y sepultó en él a varios operarios» ${ }^{15}$. Efectivamente, como señalaba Matute, estas obras le resultaron caras a Santelises, puesto que gastó 50.000 pesos para llevarlas a cabo; aunque se equivocó respecto al éxito de las mismas, porque de acuerdo

14 Obras en las minas de Tapalpa, AIPG, Nicolás López Padilla, vol. 1, f. 23v-29f; mismo notario, vol. 5 , f. 5f-12f.

15 Matute, 1879: 5. 
al testimonio del minero, le dio tan buenos dividendos que al término de dos años cubrió todos los gastos ${ }^{16}$.

El mismo Santelises informaba que gastaba 80.000 pesos anuales en la habilitación de sus minas y haciendas de beneficio, las cuales dejaban anualmente a la corona una ganancia de 40.000 pesos por cuestiones de impuestos ${ }^{17}$. Para poder realizar estas inversiones, Santelises contó con el crédito de importantes personajes e instituciones de la Nueva Galicia y de la ciudad México. Tan sólo uno de ellos, el rico hacendado Manuel Calixto Cañedo, le prestó en una sola exhibición 50.000 pesos $^{18}$. Con el tiempo este personaje llegó a ser un importante funcionario en el Tribunal de Minería, siendo primero, uno de los cuatro consultores de ese organismo y después, fiscal del mismo hasta su muerte.

Era muy difícil para los mineros lograr un verdadero éxito en la industria minera. Sobre todo porque nunca se dio una asociación entre ellos para explotar una mina o trabajar una hacienda de beneficio. Siempre era de forma individual, lo que hacía más débil su permanencia en el negocio. Llegaron a existir lo que llamo empresas familiares mineras que utilizaron los lazos consanguíneos como estrategias comerciales para lograr una mejor estabilidad, funcionamiento y éxito en sus explotaciones. Los numerosos ejemplos de estas familias, demuestran que las explotaciones que se dieron en conjunto lograron una mayor estabilidad y duración al frente de una mina o hacienda de beneficio. Algunas familias formaron una tradición minera que abarcó hasta tres o cuatro generaciones. La división y asignación de actividades a cada uno de los miembros de la familia redituó mayores éxitos y solidez a la empresa. Uno era administrador general, otro azoguero, uno más el encargado de establecer contratos de avíos, otro podía desempeñarse como abastecedor de algunos insumos provenientes de alguna hacienda agrícola o ganadera. Aun las mujeres de la familia participaban activamente en los negocios mineros. Estas empresas son las que sostuvieron en buena medida esa industria.

Una de esas familias mineras, la Ramos Jiménez, se mantuvo durante la mayor parte del s. XVIII como propietaria de casi todas las minas de Ostoti-

16 Pago de deuda adquirida por Santelises Pablo, AIPG, Antonio de Berroa, Vol. 11 fjs. 344f-348f. Según una visita realizada en 1789, se calculaba que en los años que Santelises explotó esas minas, la ley de los metales era de 6 marcos por carga. Menéndez Valdés, 1980: 99.

17 Solicitud de préstamo presentada por Santelises Pablo, Archivo General de la Nación (AGN), General de Parte, Vol. 44 exp. 183, fojas 174v-175v.

18 Otros de sus acreedores fueron el comandante del presidio de Nayarit, el juzgado de bienes de difuntos de la audiencia de Guadalajara, la oficina del estanco de tabaco de Guadalajara, el juzgado de capellanías del arzobispado de México, el marqués del Apartado, entre otros. 
pac. Para 1709, Nicolás Ramos Jiménez y dos de sus hermanos eran los mineros más prominentes de ese real. Nicolás tenía 6 hijos legítimos. Uno de ellos, el doctor Basilio Ramos Jiménez, cura del santuario de Zapopan era el encargado de comprar el azogue en la caja de Guadalajara; aunque a veces esta función la realizaba una hija. Otro hijo, cura en Compostela, se dedicaba a comprar granos y animales para la hacienda de beneficio de su padre. Un tercer hijo se desempeñaba como el azoguero de la hacienda. A mediados del siglo, con la muerte del fundador de esta extirpe minera, otro de sus hijos que había fungido como el administrador, se hizo cargo de la empresa. Todavía en 1773, dos de los nietos eran los propietarios de las principales minas de ese real ${ }^{19}$. Varias familias destacaron en otros reales como los Robles y Sánchez Calderón en Etzatlán; los Zuzuarregui, Espinoza de los Monteros, Zertucha y Mazariegos en Hostotipaquillo; los López Portillo en Jolapa, El Rosario y Chimaltitán.

La estructura productiva de la plata necesitó grandes inversiones destinadas a la excavación de tiros y socavones, construcción de pilares, ademar las paredes y techos de los túneles; pero, sobre todo, requirió de la construcción de haciendas donde se beneficiara el mineral. No todos los mineros tuvieron la capacidad económica para contar con una, esto hizo que tuvieran que llevar su mineral a moler y beneficiar a otras, o bien rentar alguna, con el inminente aumento en los gastos de obtención de plata. Existieron muchos propietarios de pequeñas haciendas de beneficio que prácticamente se dedicaban a la renta de sus instalaciones. Algunos cuando decidían hacer mejoras a sus propiedades, las rentaban a cambio de que el arrendatario pagara la renta con la construcción de casas, acequias, molinos, etc. El precio promedio anual de la renta de estos pequeños molinos oscilaba entre los 500 y 600 pesos.

Las haciendas más grandes se dedicaban a moler los minerales de un conjunto de mineros a cambio de un porcentaje de la plata obtenida o mediante la fijación de un costo que era pagado en efectivo. En los primeros años del siglo XVIII, el dueño de la hacienda de Amasaque cobraba 6 pesos de oro común por la molienda de cada 15 quintales de mineral y el trabajo requerido en la obtención de la plata. El dueño del metal tenía que pagar aparte, el consumo de azogue, sal y magistral ${ }^{20}$. El real de Guachinango fue el que más haciendas de beneficio mantuvo trabajando y el que concentró la mayor cantidad de molienda de mineral proveniente de numerosas minas. Durante la tercera década de ese siglo, el dueño de la hacienda de Santiago del Parnaso

19 Libro de repartimiento de azogues en la caja de Guadalajara, BPEJ-RAG, Ramo Fiscal, expediente 25-1749.

20 Contrato para moler metales, BPEJ-RAG, Ramo Civil, expediente 59-2-747. 
beneficiaba los minerales de 5 minas diferentes. En ese distrito minero existieron un total de 7 haciendas de beneficio que cubrían las necesidades de unas 35 minas aproximadamente. La hacienda de San Nicolás en el distrito minero de Ahualulco, molía los minerales de 6 minas, mientras que las dos existentes en Etzatlán hacían lo mismo con 11 minas. En Hostotipaquillo y Jora existieron sólo 4 haciendas que beneficiaban los metales de todas las minas de ese distrito.

La infraestructura de las haciendas de beneficio estuvo determinada por las condiciones geográficas donde se encontraban. La mayoría de ellas estaban ubicadas en las cercanías de ríos o afluentes lo que fijaba el tipo de fuerza motriz utilizada. Era obvio que en los reales de minas situados al norte de la Nueva España donde el agua no era muy abundante, se utilizara más la fuerza animal que la hidráulica, mientras que en los que aquí estudiamos es más común ésta que la animal, sobre todo en las haciendas de beneficio. Aunque una de las más importantes, como fue la de La Mololoa en Hostotipaquillo, utilizaba exclusivamente la fuerza animal para su mortero y tahonas ${ }^{21}$. La tecnología estuvo muy adelantada en algunos aspectos, por ejemplo en la utilización de tahonas para una mejor molienda, mientras que en otros reales como el de Real del Monte, a pesar de su riqueza e importancia, todavía no los conocían ${ }^{22}$. Todas las haciendas de beneficio contaban al menos con una tahona, su patio de beneficio, sus lavaderos, acequias, tomas de agua, casa de azoguería, casas para los trabajadores y bodegas donde se guardaba la herramienta, la sal y el azogue.

\section{ABASTECIMIENTO DE INSUMOS}

La constante explotación de esas minas trajo como consecuencia la formación de circuitos comerciales en los que participaba un grupo heterogéneo de abastecedores. Los hacendados agrícolas y ganaderos surtían de granos y ganados, los indígenas llevaban a vender una gran cantidad de productos como loza, frutas, legumbres, maderas, leña, carbón, aves, mieles, pescados y mariscos. Un grupo numeroso de comerciantes los surtía de una variedad de géneros que provenían de toda la Nueva España, Europa y Asia:

21 Fuerza motriz en la hacienda La Mololoa, AIPG, Manuel de Mena, vol. 10, f $625 \mathrm{v}-628 \mathrm{f}$.

22 A principios del siglo XIX, Humboldt escribió que «en algunas principales haciendas de plata de Nueva España, por ejemplo en Regla, no se conocen aún las atahonas; se contentan todavía con el uso de los mazos...» Humboldt, 1991: 375. 
ropa, azúcar, sal, aceite, herramientas de fierro, sogas, telas, ropa, vino de Castilla, vino mezcal, tabaco, especias, etcétera. La corona por su parte, controlaba el mayor y más importante circuito comercial: el abasto de azogue. La explicación y funcionamiento de cada una de estas redes de abastecimiento requiere de un mayor espacio que un artículo, por eso me enfocaré en abordar en específico el abastecimiento de azogue a la caja real de Guadalajara.

El azogue consumido en las minas de la caja de Guadalajara durante el siglo XVIII provino principalmente de las minas de Almaden. Cuando esas minas entraban en crisis, era necesario recurrir a las minas de Huancavelica en el Perú. Los mineros de la región aquí estudiada recurrieron sólo en tres ocasiones $(1700,1741$ y 1754$)$ a ese producto que no era muy requerido debido a que resultaba más caro y rendía menos que el de Almaden ${ }^{23}$. A partir de 1786 y hasta 1804 una buena parte del azogue consumido en esas minas llegó también de Alemania.

El azogue, una vez depositado en Veracruz, era trasladado a la sede de la superintendencia de azogues que estuvo en la ciudad de Puebla desde 1709 hasta 1740 ya que al año siguiente fue trasladada a la ciudad de México. El administrador general era el encargado de decidir las cantidades que se repartirían a cada caja real después de analizar las necesidades de cada centro minero, pero sobre todo, la cantidad entregada a cada caja real dependía de la cantidad de azogue que llegaba a la Nueva España, tratando siempre de cubrir en primer lugar las demandas de los centros mineros más importantes. Por eso las cantidades de azogue para la caja de Guadalajara no son uniformes, son muy desiguales como se puede observar en la siguiente gráfica. El cuadro que sigue a la gráfica presenta el porcentaje de azogue que se destinó a la caja de Guadalajara respecto a las otras cajas reales.

Cuando el azogue se encontraba en la caja de Guadalajara, acudían a ella todos los mineros o sus apoderados para comprarlo. Las cantidades de azogue vendidas a cada minero estaban determinadas por la cantidad de marcos de plata que cada uno de ellos presentaba a quintar conforme al monto anterior de mercurio que se le había vendido. Esta es la razón por la cual aparecen separados los impuestos recaudados de ambas platas aunque pagaran lo mismo. Los de la caja de Guadalajara estuvieron obligados a diezmar 125 marcos de plata por cada quintal que se les había repartido y a partir de 1740, se les rebajó esa cantidad a 115 marcos. Una cantidad demasiado alta si tomamos en cuenta lo que se les exigía a los de otras jurisdic-

${ }^{23}$ Lang, XLVIII / 4 (Durham, USA, 1968): 640. 
GrÁFICA 2. Azogue ENTREGAdo EN LA CAJA DE GuAdALAJARA 1709-1753

Quintales

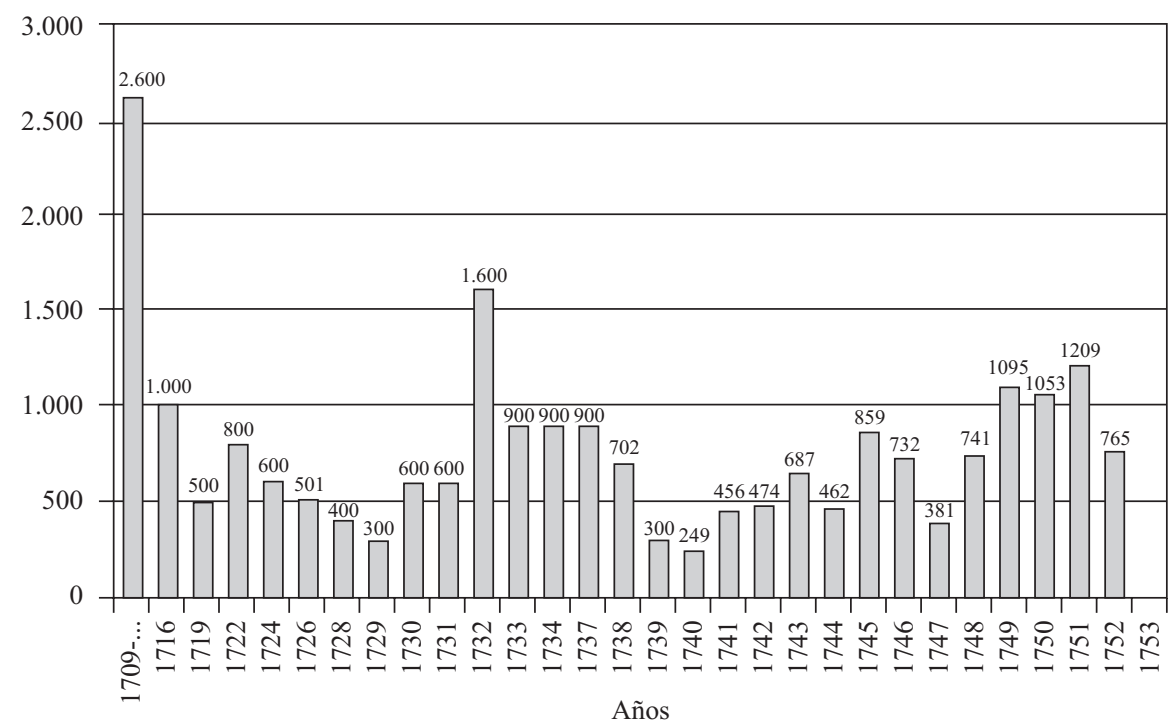

Fuente: Heredia Herrera, 1978: 243-244.

CUAdro 1. Distribución PORCENTUAL DE los REPARTOS DE AZOGUE A LA CAJA DE GUADALAJARA 1755-1805

\begin{tabular}{|c|c|}
\hline Año & Porcentaje \\
\hline 1755 & 10,3 \\
1760 & 7,7 \\
1765 & 21,3 \\
1770 & 10,4 \\
1775 & 11,4 \\
1780 & n.i \\
1785 & 7,6 \\
1790 & 6 \\
1795 & 6 \\
1800 & 6,6 \\
1805 & 4 \\
\hline
\end{tabular}

Fuente: Sánchez Gómez, 1997: 443. 
ciones. Por ejemplo los de Zacatecas, Sombrerete y Pachuca tenían que presentar 100 marcos por quintal, a los de Taxco, Chautla de la Sal, Zacualpa, Tlalpujagua y Guautla 90 marcos, a los de Temascaltepec 85 marcos. Sólo a los de Guanajuato y Comanja se les pedía más que a los de Guadalajara: 125 marcos.

El azogue se vendía siempre a crédito con un plazo de 6 meses, mediante la firma de una libranza. El minero pagaba el monto con plata en pasta a un receptor que acudía a cada real a realizar el cobro. El plazo de 6 meses estaba determinado porque era el tiempo calculado en que tardaba el minero en beneficiar su mineral y obtener la plata en pasta. La venta sólo se le hacía a los mineros o a sus apoderados que eran además sus aviadores. El precio por quintal permaneció fijo desde 1627 hasta 1767 en 60 ducados de Castilla que equivalían a 82 pesos 5 tomines 9 granos. A este importe se le agregaban los costos de traslado desde la superintendencia de azogues a la caja real, que eran absorbidos por los mineros. De modo que el precio de cada quintal vendido en Guadalajara era de 90 pesos el de Almaden y 111-7-6 el de Perú. Todavía falta agregar el costo de traslado a cada real de minas. A partir de 1768 el costo por quintal puesto en la superintendencia de azogues bajó a 62 pesos 4 granos. Esta rebaja se dio dentro de las reformas impulsadas por el visitador José de Gálvez ${ }^{24}$. Si comparamos la entrega de azogue con los ingresos exclusivos de plata de azogue, podemos ver que hay una correspondencia en donde a mayor azogue entregado, mayor recaudación y viceversa. La siguiente gráfica muestra las cantidades que ingresaron a la caja de Guadalajara por concepto de la venta del azogue.

El abasto de azogue a los distintos reales de minas benefició de gran manera a los arrieros que eran contratados para su traslado, pues aprovechaban el viaje para llevar a vender otra serie de mercancías. Pero sobre todo, creo que se beneficiaron mucho con el tráfico ilegal que hacían del mercurio ante la gran demanda que tenía por su escasez. Cuando ellos declaraban la pérdida de alguno o varios quintales, la corona les cobraba exclusivamente el valor de cada quintal. Es lógico suponer que lo escondían durante el trayecto para luego revenderlo a los mineros.

24 Velasco Ávila, 1987: 68. 
Gráfica 3. Pesos Recaudados en la caja de Guadalajara por venta DE AZOGUE 1700-1804

Pesos

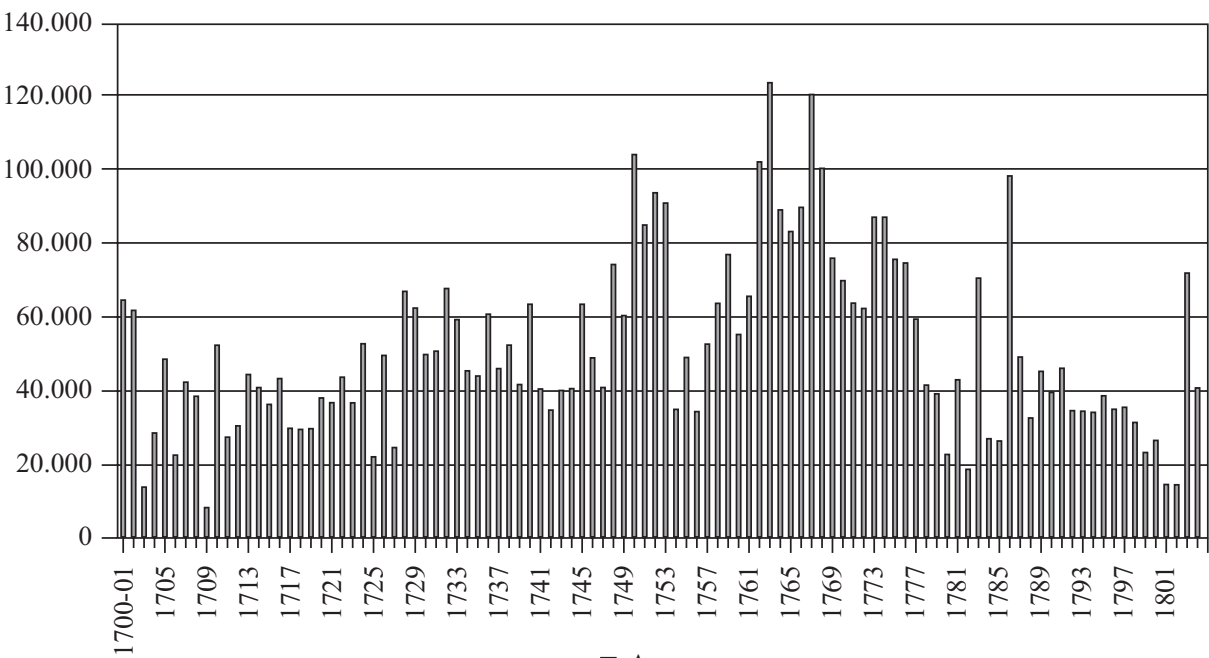

$\square$ Azogues

Fuente: Archivo General de Indias (AGI), Contaduría, 872.

\section{PRODUCCIÓN DE PLATA}

Las minas de la caja de Guadalajara fueron principalmente de plata y aunque se sacaba oro, la presencia de éste alcanzó relativa importancia en la segunda mitad del siglo XVIII. El propósito de este apartado es dar a conocer una serie de datos fiscales que nos permitan imaginar las cantidades que esas explotaciones produjeron durante el siglo XVIII y que convirtieron a la industria minera en la principal fuente de ingresos de aquella receptoría en todo ese siglo. Para ello utilizo las cifras recaudadas en la caja real de Guadalajara de todos los impuestos de plata y oro ( $1 \%$ y diezmo de ambas platas, $1,5 \%$ y quinto del oro, señoreaje de oro y plata, plata y oro labrado) y lo cobrado por concepto de venta de azogue. La contabilidad corresponde desde 1703 hasta 1804 en años fiscales de 12 meses que van de enero a diciembre. Sólo los de 1700-1701 y 1701-1702 comprenden 18 meses. Como complemento, añado algunos detalles sobre la producción de algunas minas o reales y la calidad de sus metales. 
El total recaudado en aquella caja durante 105 años fue de 50.657,400 pesos de ocho reales, de los cuales 15.830,094 pesos correspondieron a los conceptos arriba señalados. En la siguiente gráfica se puede apreciar el alto porcentaje (31\%) de ingresos que se obtuvieron directamente de la minería. Esta industria tuvo también una influencia considerable en los ingresos provenientes del apartado «varias entradas», debido a la actividad comercial que generó la demanda de diversos productos en los reales de minas y que influyó en el apartado de alcabalas y, sobre todo, en los de vino mezcal y tabaco. Al menos durante los primeros 60 años de ese siglo, el porcentaje de ingresos provenientes de la minería fue mucho más alto. De hecho en varios años, lo recaudado por esa industria superó los ingresos de todos los otros ramos juntos. Lo sucedido después fue que algunos productos alcanzaron gran importancia comercial generando altas sumas de ingresos fiscales que ocasionaron que la brecha porcentual entre minería y «varias entradas» se ampliara. Me refiero en específico a los ingresos obtenidos en el último tercio de esa centuria, de los ramos de vino mezcal y de tabaco. La gráfica 5 demuestra cómo en la última parte del siglo, el porcentaje de ingresos provenientes de la minería disminuyó considerablemente, pero no debido al agotamiento de las vetas ${ }^{25}$.

El cálculo de la producción de plata en los reales de minas de la caja de Guadalajara lo hice exclusivamente con las cantidades recaudadas por concepto del impuesto del diezmo y $1 \%$ que se cobraba sobre la plata presentada a los oficiales reales. No tomo en cuenta otro tipo de impuestos porque considero que no son indicadores de lo producido en ellas. Ruiz Medrano señala que el derecho de vajilla o plata labrada puede ser un indicativo de lo producido en la minería ${ }^{26}$. No coincido con el autor porque no hay una correlación entre la cantidad de plata labrada y la producida. Además, la plata presentada en la caja de Guadalajara para ser labrada no era necesariamente originaria de los reales de minas de esa jurisdicción. El impuesto de señoreaje que me permite conocer las cantidades de marcos de plata amonedados, tampoco me ayuda a calcular la producción de plata porque no toda se amonedaba.

${ }^{25}$ La caída en la recaudación a fines del siglo XVIII y primeros años del XIX tiene su explicación en la crisis provocada por la escasez de azogue a causa de las guerras de España con Inglaterra, como más adelante se explicará.

26 Ruiz Medrano, 2002: 112-113. Este autor señala que el derecho de vajilla o plata labrada comenzó a cobrarse en 1754, pero en los libros de cartas cuentas consultados, este impuesto está ya desde 1707. Ver Tepaske y Klein, 1986, Vol. 1: 61 y ss. 
GrÁfica 4. Porcentaje de ReCAudación en la CAJA de Guadalajara

1700-1804

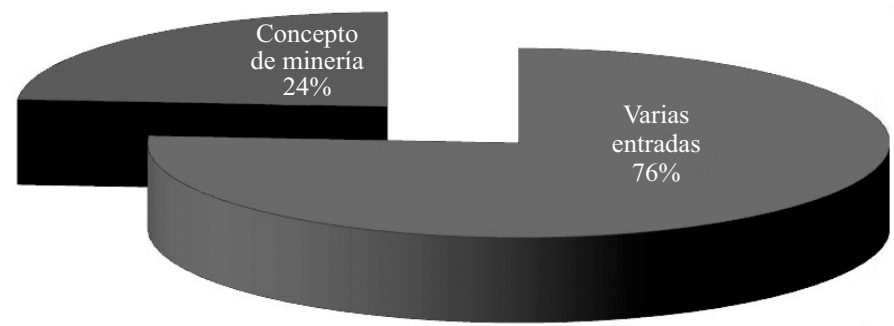

Fuente: Tepaske y Klein, 1986, vol. 1: 58-127.

GrÁFICA 5. INGRESOS DE LA CAJA DE GUADALAJARA PROVENIENTES DE MINERÍA Y OTROS RAMOS

Pesos

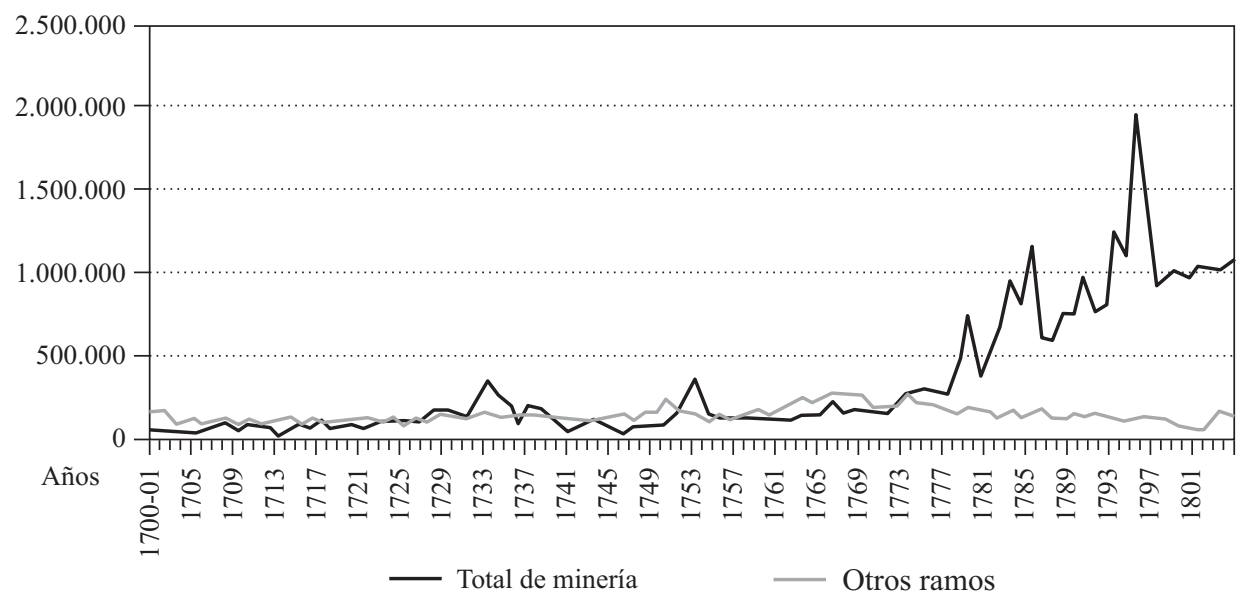

Fuente: Tepaske y Klein, 1986, vol. 1: 57-127.

Se observa cómo a partir de la segunda mitad del siglo hay un aumento considerable en la recaudación del diezmo. Esto obedece a varias razones. Una de ellas es que a partir de 1740, se les rebajó a los mineros la cantidad de marcos exigidos a diezmar por cada quintal de azogue que se les había vendido. Anteriormente era de 125 marcos y después de ese año quedó en 
115. Esto ocasionó que a los mineros les fueran vendidas mayores cantidades de azogue. Además es un periodo en donde se descubrieron nuevas y ricas vetas de plata.

GRÁFICA 6. 1\% Y DIEZMO COBRADO EN LA CAJA DE GUADALAJARA 1700-1804 Pesos

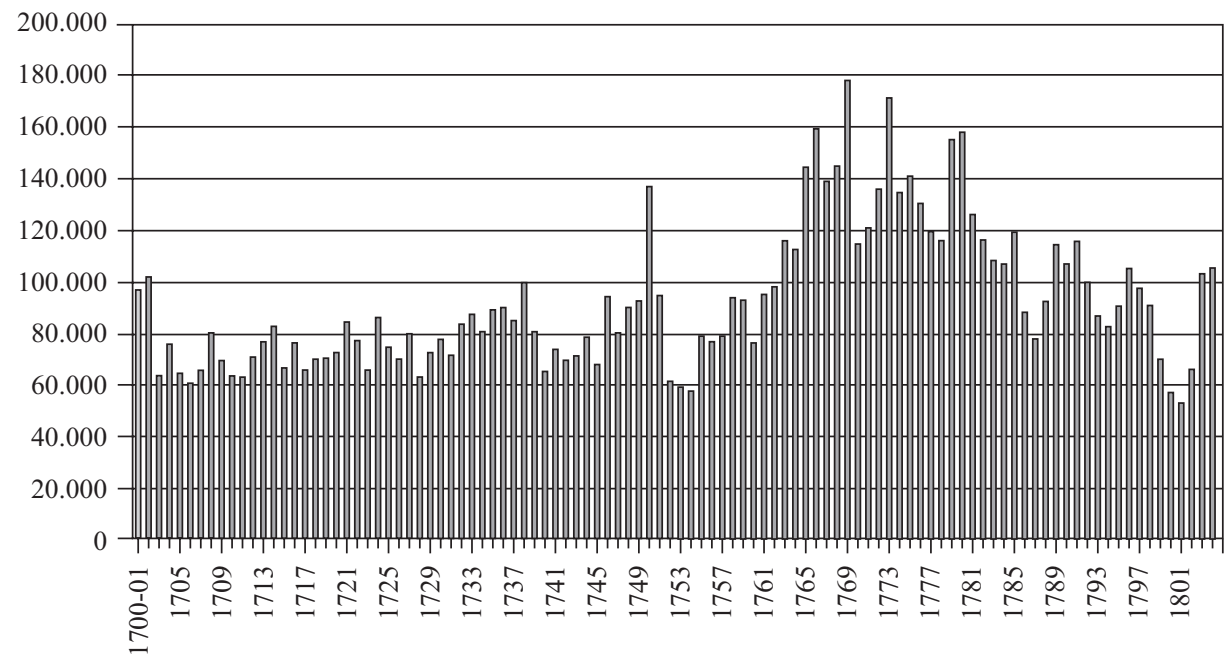

Fuente: AGI, Contaduría 442-447 y 872.

La presencia de una considerable cantidad de dinero proveniente del impuesto de la plata de fuego en la caja de Guadalajara podría analizarse a partir de la inconsistencia en los repartos de azogue a esa caja, que orillaba a muchos mineros a utilizar hornos de fundición con el fin de que el mineral extraído no se mantuviera sin beneficio y recuperar al menos parte de la inversión, aun a sabiendas de que mucha plata se desperdiciaba por este método. Por consiguiente, cuando el suministro de azogue era abundante, la producción de plata de fuego disminuía considerablemente. La gráfica siguiente muestra claramente tres momentos que confirman este sustento. A principios de la década de 1760, el mercurio llegó en abundancia a las minas de Guadalajara ocasionando un aumento en el beneficio de plata por este método y el desplome en la obtención de la de fuego. Cuando en 1784 hubo escasez de mercurio la producción de plata de fuego aumentó. Igual ocurrió en 1791, cuando la recaudación por concepto de plata de fuego superó a la de azogue. 
GRÁFICA 7. $1 \%$ Y DIEZMO COBRADO POR PLATA DE FUEGO Y AZOGUE EN GUADALAJARA

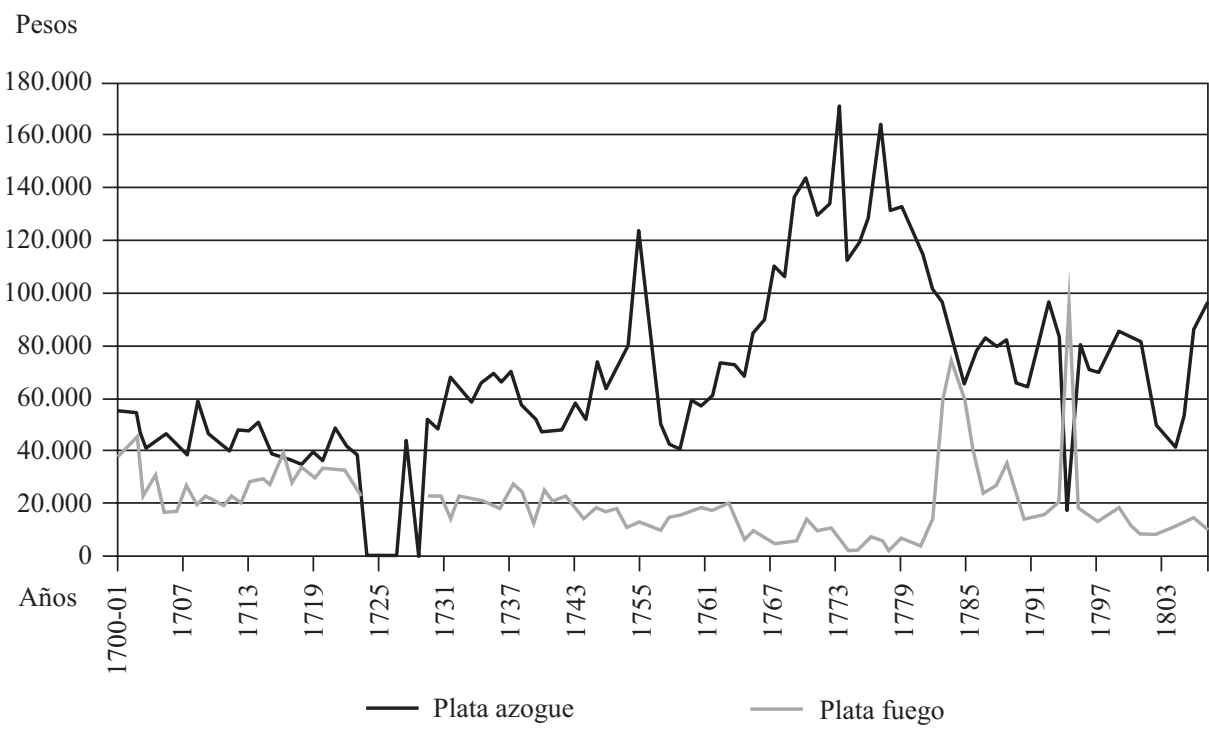

Fuente: AGI, Contaduría, 442-447 y 872.

Se debe tomar en cuenta la existencia de minerales de alta ley en esas minas, pues de 40 haciendas de beneficio, al menos ocho utilizaban el método de fuego o fundición. Además de la presencia de una gran cantidad de pequeñas fundiciones que se localizaban en las inmediaciones de las minas. Estos factores pueden explicar el alto porcentaje en la recaudación por concepto de plata de fuego. Del total de impuestos captados por ambas platas, el $22 \%$ corresponde a ésta y el resto a la de azogue.

Algunas de las fluctuaciones en la recaudación de impuestos de la plata se explican a partir de la escasez de azogue. Por ejemplo, la baja en el último año del siglo XVIII y los primeros tres del siguiente, se debieron a que no llegaba el azogue necesario para cubrir las necesidades de las minas. Ante la falta de azogue, muchas minas y haciendas de beneficio se vieron precisadas a parar sus trabajos, lo que obligó a las autoridades virreinales a tomar una serie de medidas favorables a los mineros. El virrey Miguel de Azanza decretó que los dueños de las minas que estuvieran despobladas a causa de la falta del mercurio no se verían perjudicados en la posesión de las minas y és- 
tas no podrían ser denunciadas por otras personas ${ }^{27}$. En 1801, la corona eximió del pago del impuesto del 1\% y diezmo de la plata de fuego, buscando de esta forma compensar la caída en la producción de la plata de azogue y mantener trabajando la mayor cantidad posible de minas para que la crisis no se extendiera a otras ramas de la economía como la agricultura, ganadería o el comercio ${ }^{28}$.

La causa de esta situación había sido provocada por la guerra que sostenía España con Inglaterra. En 1802, cuando la crisis alcanzó su mayor apogeo debido al bloqueo naval británico provocado por la alianza de España con $\mathrm{Na}$ poleón, el rey otorgó a la minería la reducción de la mitad de los pagos de impuestos por la plata de azogue; aunque esta medida sólo duró siete meses, pues en julio de 1802, la Nueva España comenzó a recibir grandes remesas de azogue y este decreto fue revocado ${ }^{29}$. La minería se fue recuperando a partir del segundo semestre de 1802, cuando llegaron un total de 13.593 quintales en dos remesas y mejoró aún más el año siguiente debido a que en enero de 1803 llegaron desde Almaden, 12.000 quintales $^{30}$.

La producción en conjunto de estos «realitos» y su explotación continuaría a lo largo del siglo XVIII, fueron factores fundamentales para la consolidación de la economía regional de la Nueva Galicia al crear redes mercantiles que impulsaron a otras industrias como la agricultura, la ganadería y sobre todo al comercio. Las cifras producidas año con año en esos reales demuestran lo equivocados que están diferentes historiadores locales cuando afirman que la minería en la región de Guadalajara no tuvo mucha importancia. La producción constante demuestra que esa industria no vivió graves crisis como en otras cajas reales. Esto se explica en razón de que mientras algunos reales entraban en periodos de borrasca, surgían nuevos descubrimientos que permitían mantener un promedio constante en la recaudación de impuestos.

27 Decreto librado en 1797 por el virrey Miguel de Azanza, referente a que el despueble de las minas por falta de azogue no perjudica a los mineros en la posesión de sus minas. Archivo Histórico del Palacio de Minería (AHPM), 1800/I/104/d.37.

28 Sobre exención del diezmo y uno por ciento de las platas beneficiadas por fuego. México, a 2 de diciembre de 1801, (AHPM) 1801/III/111/d.28.

29 Condonación que el rey otorgó a la minería de los medios derechos de diezmo y el 1\% en todas las platas, del $1 .^{\circ}$ de enero al 31 de julio de 1802. Zitácuaro, a 28 de noviembre de 1803, (AHPM) 1803/III/121/d.10.

30 Sobre la llegada de 5,592 quintales de azogue al puerto de Veracruz, en la urca nombrada la Brújula. Tlalpujahua, a 12 de junio de 1802, (AHPM) 1802/IV/116/d.3; Repartimiento de ocho mil y un quintal de azogue. México, a 6 de febrero de 1802 (AHPM) 1802/VI/ 118/d.28; Llegada de 12000 quintales en los navios San Julián, El Miño y Presentación, a Veracruz. Zacualpan, a 12 de enero de 1803, (AHPM) 1803/III/121/d.34. 
Gráfica 8. Producción de Plata en la Caja de Guadalajara 1700-1804

Pesos

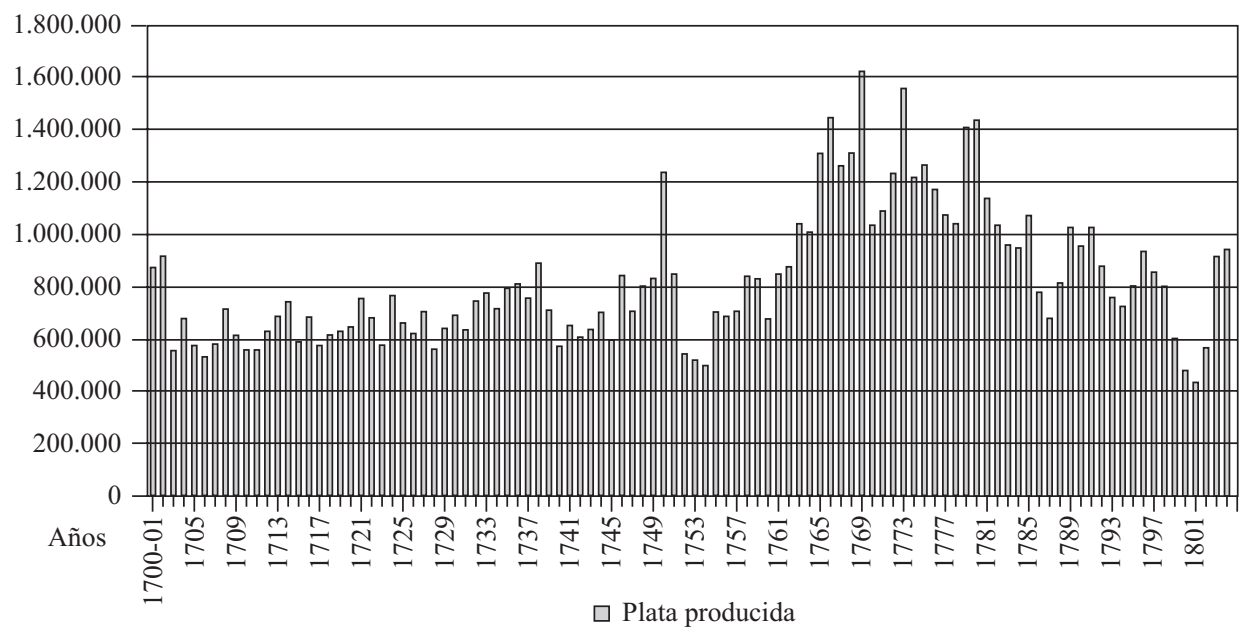

Fuente: Calculada a partir del 1\% y diezmo pagado.

Por una descripción que se hizo de algunos reales de minas entre 1789 y 1793 se puede conocer un aproximado de lo que producían algunas minas por jurisdicción. Las de San Sebastián que incluían cuatro reales, eran las más ricas pues rendían de 50 a 60 mil marcos de plata. Tan sólo de un ojo de metal que fue encontrado en 1788 se sacaron en tres semanas más de doscientos mil pesos, aunque se agotó inmediatamente. De Tres pequeños reales de la jurisdicción de Acaponeta (Motage, Tule y Frontal) se obtenían entre 4 y 5 mil marcos. Los de Chimaltitán, Acuitapilco y El Liso en la jurisdicción de Santa María del Oro rendían 4 mil marcos. El real de Hostotipaquillo de 6 a 8 mil marcos. Las de San Pedro Analco en Tequila, 1.300 marcos. Las de Etzatlán 20.000 marcos $^{31}$. La suma y conversión de estos marcos en pesos nos daría un estimado de 767.550 pesos anuales. Tomando en cuenta que el visitador no aportó datos para otros reales como Guachinango, calculo que la producción anual de todos esos reales estaría entre los 850 y 900 mil pesos.

Gracias a los libros de libranzas de azogue que se encuentran en la Biblioteca Pública del Estado de Jalisco, podemos hacer un ejercicio para estimar lo que un real de minas producía, tomando como base mínima los 115 marcos de

31 Menéndez Valdés, 1980: 79-98. 
plata que se les exigían por cada quintal de azogue. Veamos por ejemplo, al real de Ostotipac que fue uno de los más ricos y de los que mayor cantidad de azogue recibieron. En 28 años a ese real se le vendieron 1.987,5 quintales que debieron producir como mínimo 228,562 marcos de plata que multiplicados por 8,5 pesos (valor de cada marco), nos da un estimado de 1.942,781 pesos que divididos entre los 28 años, promedia anualmente 69.000 .385 pesos.

El impuesto de señoreaje nos permite conocer las cantidades de marcos de plata amonedados y, por consiguiente, el circulante en moneda que llegaba a Guadalajara y se distribuía en las distintas regiones. Esta moneda junto con la plata marcada, utilizada por los mineros para pagar a los comerciantes, contribuyó a la consolidación de la economía regional de la intendencia de Guadalajara ${ }^{32}$.

El gravamen de señoreaje aparece asentado por primera vez en los libros fiscales de la caja de Guadalajara en 1700 y llega hasta el año de 1766, cuando se cobró por última ocasión en las cajas reales. Tenemos que si por cada marco de plata destinado a ser amonedado se cobraba un real, la cantidad de pesos recaudada por este impuesto la multiplicamos por 8 que es el número de reales que componen un peso y el resultado es la cantidad de marcos amonedados. Multiplicada esa cantidad de marcos por 8.5 pesos (valor de cada marco) tenemos el total de pesos amonedados. Las siguientes cuatro gráficas muestran los pesos recaudados por el impuesto de señoreaje, la cantidad de marcos amonedados, el valor en pesos de la plata amonedada y el porcentaje de la plata destinada a amonedarse y la que tenía otro destino ${ }^{33}$.

Calculando el porcentaje de plata que se amonedaba de la que se producía (a partir del estimado que hice) vemos como un $85 \%$ aproximadamente se destinaba a ese fin. La siguiente gráfica muestra ese porcentaje desde el año de 1700 en que aparece por primera vez el impuesto de señoreaje hasta 1766 en que fue la última vez que se cobró en la caja de Guadalajara, con el estimado realizado de producción total de plata durante esos años ${ }^{34}$. El total calculado de plata producida de 1700 a 1766 fue de 48,626,908 pesos. Lo que se destinó para amonedarse ascendió a 41,220852 pesos.

32 Ante la alta circulación de plata en barras, la corona implementó el sistema mediante el cual un funcionario llamado receptor acudía a los reales de minas para sellar la plata extraída y que ésta pudiera circular libremente aunque todavía no hubiera pagado el diezmo. Pérez Herrero, 1988 , p. 113.

33 No se incluyen los años de 1724 y 1725 debido a que ese impuesto se incluyó en el monto total del impuesto del diezmo de plata. 
GrÁFICA 9. IMPUESTO DE SEÑOREAJE DE PLATA COBRADO EN LA CAJA DE GUADALAJARA 1700-1766

Pesos

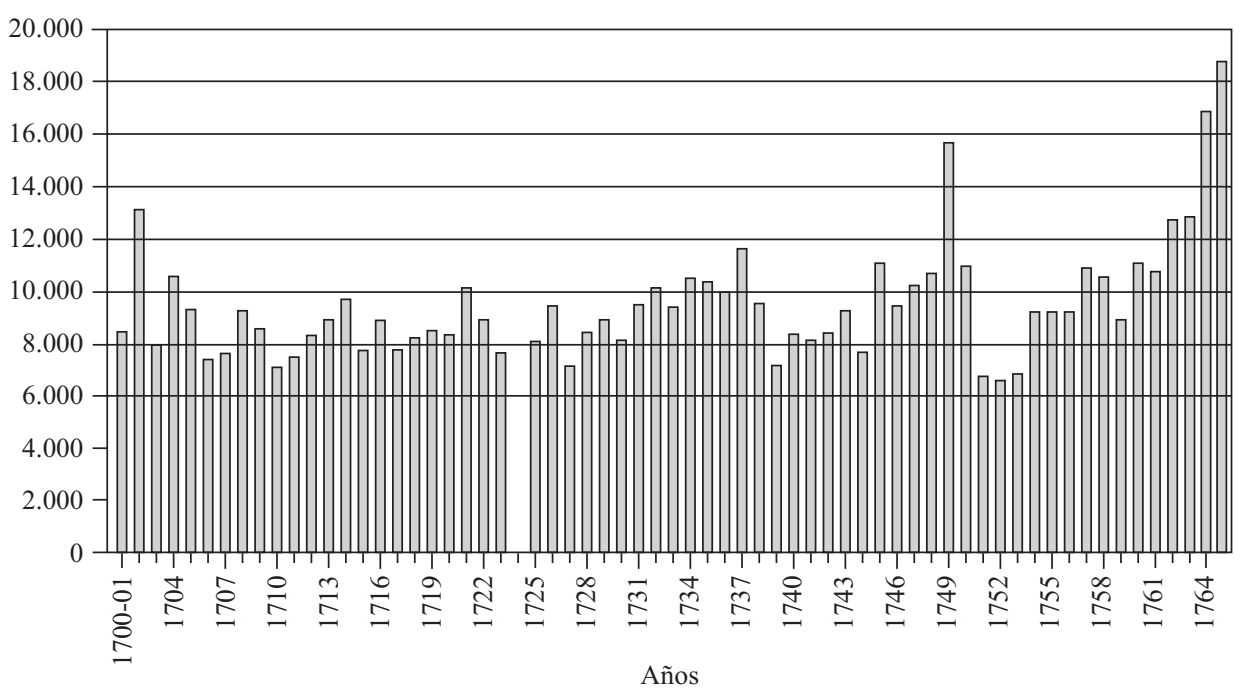

Fuente: AGI, Contaduría, 442-447 y 872.

GráFicA 10. Marcos DE PLATA ENVIADOS A AMONEDAR DESDE LA CAJA DE GUADALAJARA 1700-1766

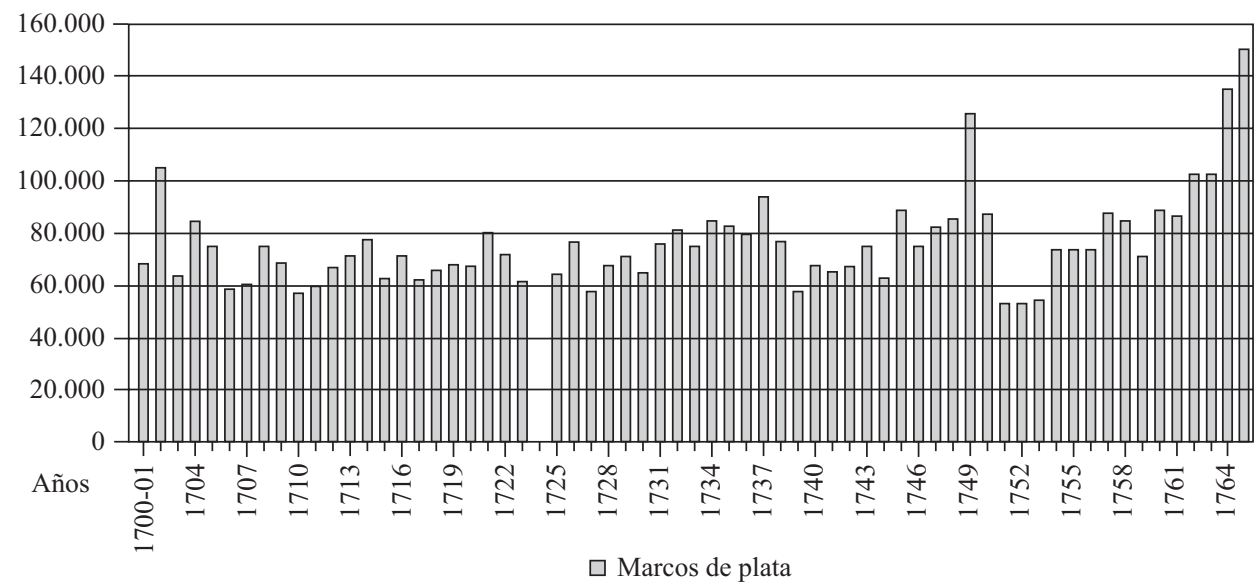

Calculado a partir de los pesos ingresados por el impuesto de señoreaje. 
Gráfica 11. Pesos amonedados de plata Para la caja de Guadalajara $1700-1760$

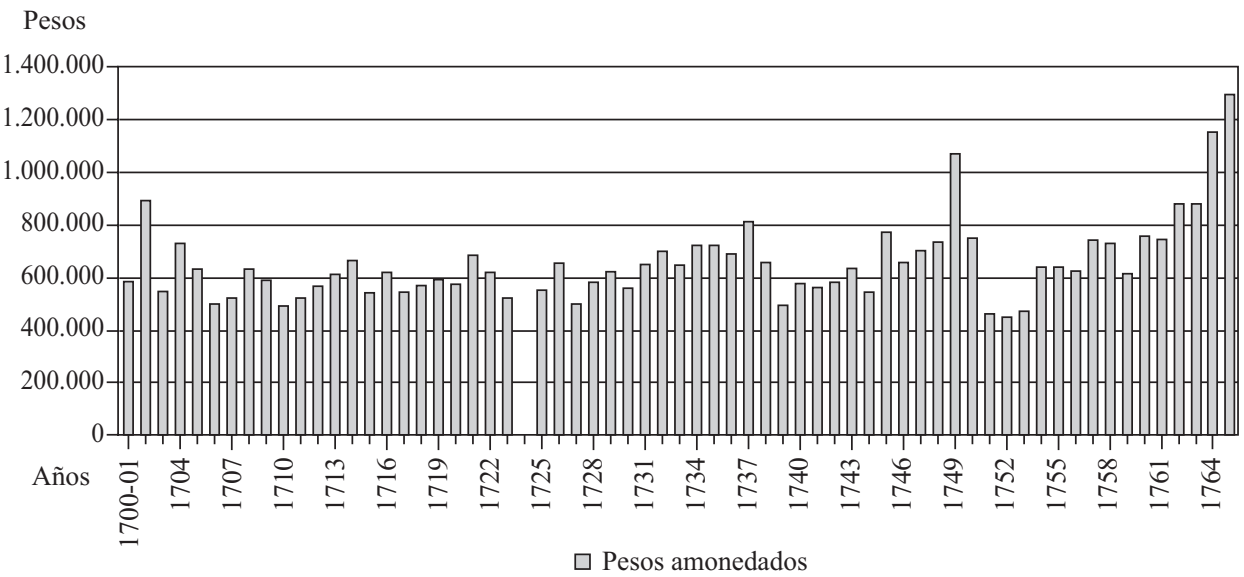

Calculado a partir de los marcos enviados a amonedar.

GrÁfica 12. Porcentaje DEL DESTINO DE LA Plata PRESENTADA EN LA CAJA DE GUADALAJARA

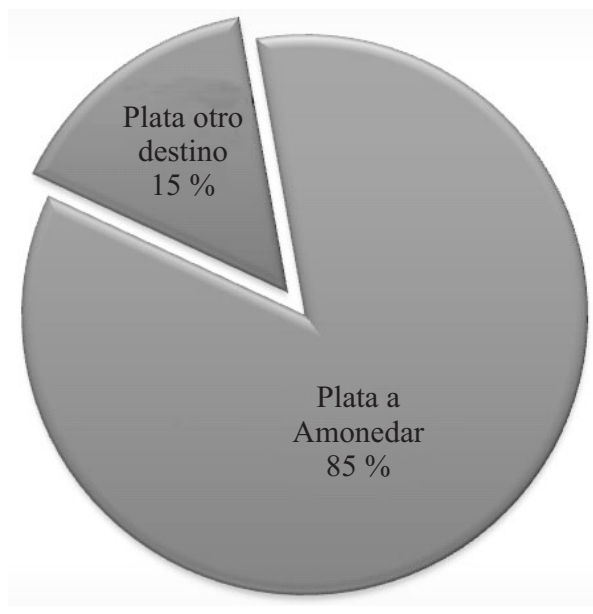

Fuente: AGI, Contaduría, $442-447$ y 872. 


\section{REFLEXIÓN FINAL}

Resumir en un artículo el funcionamiento de una considerable cantidad de reales de minas y haciendas de beneficio que existieron a lo largo del siglo XVIII en la jurisdicción de la caja de Guadalajara, nos obliga a dejar de lado una serie de temas relevantes de esa industria, ya que su estudio o análisis requeriría un espacio mayor. Este trabajo se une (lamentablemente) a la larga lista de estudios que tratan exclusivamente la producción de plata, dejando de lado el estudio de la industria del oro. De momento, sólo puedo señalar que en los distritos aquí estudiados hubo una constante explotación de ese metal que produjo tan sólo por concepto de impuestos 274.428 pesos en el periodo de 1700 a 1766 cuando se cobraba el 1.5\% y diezmo. Al año siguiente se modificó el porcentaje de impuesto quedando establecido en 3\%, generando para la corona por ese concepto 24.948 pesos en el lapso de 1767-1804.

Otro tema que quedó sin tratar fue el de la mano de obra. A diferencia de la primera mitad del siglo XVII en donde la minería de la Nueva Galicia sufrió una grave crisis a consecuencia de la casi desaparición de los indios, durante el siglo XVIII la influencia de esta mano de obra merece ser estudiada en sus diferentes acepciones: libre asalariada, retención por deudas y por repartimiento forzado. La alta concentración de mano de obra esclava merece un estudio individual, lo mismo que el análisis de la presencia de mujeres trabajadoras.

El estudio de los circuitos comerciales implementados a partir del desarrollo de la industria minera puede ser abordado a partir del análisis de un determinado producto como la sal, vino mezcal, mariscos y pescados, ganado o algún producto agrícola. El tema de los arrieros y su importancia como distribuidores de los insumos necesarios para la minería y costos de traslado también queda pendiente. La formación de complejos minero-agroganaderos que permitieron a varios propietarios de minas amasar una gran fortuna y llegar a formar parte de la elite de Guadalajara y su región, merece un artículo aparte.

\section{BIBLIOGRAFÍA}

Grenow, Linda, «Dimensiones espaciales del mercado de crédito en la nueva Galicia del siglo XVIII», Revista Jalisco, núm. 3, Guadalajara, 1980: 69-75.

Gutiérrez y Ulloa, Antonio, Ensayo histórico político del reino de la Nueva Galicia, con notas politicas y estadísticas de la provincia de Guadalajara, Guadalajara, Ayuntamiento de Guadalajara, 1983.

Heredia Herrera, Antonia, La renta del azogue en Nueva España (1709-1751), Sevi1la, Escuela de Estudios Hispanoamericanos de Sevilla, 1978. 
Humboldt, Alejandro de, Ensayo político sobre el reino de la Nueva España, México, Porrúa, 1991.

Lang, M. F., «New Spain’s mining depression and the supply of quicksilver from Peru 1600-1700», Hispanic American Historical Review, vol. XLVIII, núm. 4, Durham, 1968: 632-641.

Lang, M. F., El Monopolio Estatal del Mercurio en el México Colonial (1500-1710), México, Fondo de Cultura Económica, 1977.

Matute, Juan Ignacio, Informe rendido por el Sr. [...], ante la junta directiva de la compañía minera de San Rafael, por motivo de la posesión que se dio de aquel distrito minero a dicha compañia, por el juez letrado de Sayula, Guadalajara, Tip. de M. Pérez Lete, 1879.

Menéndez Valdés, José, Descripción y censo de la intendencia de Guadalajara, 1789-1793, Guadalajara, Unidad Editorial del Gobierno del Estado de Jalisco, 1980.

Muñoz, Diego, Descripción de la provincia de San Pedro y San Pablo de Michoacán, en las Indias de la Nueva España, Crónica del siglo XVI, Guadalajara, Imprenta «Gráfica», 1950.

Pérez Herrero, Pedro, Plata y libranzas, la articulación comercial del México Borbónico, México, El Colegio de México, 1988.

Ruiz Medrano, Carlos Rubén, Plata labrada en la real hacienda: estudio fiscal novohispano, 1739-1800, México, INAH, 2002.

Sánchez Gómez, Julio, Guillermo Mira Delli-Zotti y Rafael Dobado,La Savia del imperio. Tres estudios de economía colonial, Salamanca, Universidad de Salamanca, 1997.

Serrera, Ramón María, Guadalajara ganadera, estudio regional novohispano (1760-1805), Guadalajara, Ayuntamiento de Guadalajara, 1992.

Tello, Fray Antonio, Crónica Miscelánea y Conquista Espiritual y Temporal de la Santa Provincia de Xalisco en el Reino de la Nueva Galicia, vol. 2, Guadalajara, Gobierno de Jalisco-Universidad de Guadalajara-INAH, 1968.

Tepaske, John Jay y Herbert S. Klein, Ingresos y egresos de la Real Hacienda de la Nueva España, vol. 1. México, INAH, 1986.

Van Young, Eric, La ciudad y el campo en el México del siglo XVIII. La economía rural de la región de Guadalajara, 1675-1820, México, Fondo de Cultura Económica, 1989.

Velasco Ávila, Cuauhtémoc, et al., Estado y minería en México (1767-1910), México, SEMIP-INAH, 1987.

Fecha de recepción: 29 de septiembre de 2010

Fecha de aceptación: 2 de diciembre de 2010 


\section{Reales de minas (groups of mines) of the «Caja de Guadalajara» during the $18^{\text {th }}$ century: trade routes and silver production}

This article shows the economic significance of the group of mines that belonged to the jurisdiction of the "Caja de Guadalajara». The novelty lies in that local historiography had erroneously labeled these mining camps as being small. Recent studies show that they were not so small after all. These groups of mines were the focal point of the economy of a vast region and triggered the development of agriculture, livestock and trade activities. This article reveals the nexus between the fluctuations in silver production and events in Europe.

KEY WORDS: Silver; aviators; miners; trade; mercury. 